\title{
Entre el beneficio, el compromiso y la oportunidad: la importancia de la educación para los participantes de un taller de alfabetización de una cárcel bonaerense
}

Camila Pérez - Universidad Nacional de San Martín - UNSAM

0000-0002-9703-3348

Recepción: 23.02.2021 | Aceptado: 01.03.2021

Correspondencia a través de ORCID: Camila Pérez

0000-0002-9703-3348

Citar: Pérez, C (2021). Entre el beneficio, el compromiso y la oportunidad: la importancia de la educación para los participantes de un taller de alfabetización de una cárcel bonaerense. REIDOCREA, 10(15), 1-20.

Resumen: Este artículo propone un acercamiento a la vida cotidiana de un taller de alfabetización que transcurrió en el año 2017 en una cárcel de la Provincia de Buenos Aires, Argentina. Específicamente me interesa analizar cómo las interacciones que se producen en el espacio escolar resultan una condensación y un reflejo de las relaciones que se viven en el resto del Penal. Desde un análisis etnográfico me propongo demostrar cómo las conflictividades y violencias inherentes al espacio carcelario son recuperadas y reelaboradas por las personas privadas de su libertad que logran acceder a un cupo para participar del taller y que encuentran allí una oportunidad de hacerse amigos, olvidarse momentáneamente de los problemas del pabellón y aprender a cuidar y respetar ese espacio educativo.

Palabra clave: Educación correccional

Between the benefit, the commitment, and the opportunity: the importance of education for the participants of a literacy workshop in a Buenos Aires prison

Abstract: This article proposes an approach to the daily life of a literacy workshop that took place in 2017 in a prison in the Province of Buenos Aires, Argentina. Specifically, I am interested in analyzing how the interactions that occur in the school space are a condensation and a reflection of the relationships that are experienced in the rest of the prison. From an ethnographic analysis, I will demonstrate how the conflicts and violence inherent in the prison space are recovered and reworked by the people deprived of their liberty who get a place to participate in the workshop and who find there an opportunity to make friends, momentarily forget the problems of the prison and learn to care for and respect that educational space.

Keyword: Correctional education

\section{Introducción}

En Argentina la educación en las cárceles fue definida como un derecho por la Ley Nacional de Educación 26.206 sancionada en el 2006 (Frejtman y Herrera, 2010). Esta iniciativa se vio reforzada por la modificación de los artículos 133 a 142 de la Ley Nacional de Ejecución Penal 24.660 en agosto del 2011 (con la sanción de Ley 26.695). A partir de estos cambios se promovió, a través del artículo 140, el estímulo educativo, figura que busca favorecer el avance en diferentes fases de la progresividad de la pena si el estudiante logra completar un ciclo lectivo anual, un curso de formación profesional o cursos de estudios superiores (Pérez, 2019b).

Por otro lado, el Informe Anual 2017 del Sistema Nacional de Estadísticas sobre Ejecución de la Pena (SNEEP) estimó, para el año 2017, una población total de 76.261 personas privadas de la libertad de las cuales más del $44 \%$ se encontraba alojada en cárceles de la Provincia de Buenos Aires gestionadas por el Servicio Penitenciario Bonaerense. El $61 \%$ de la población privada de libertad era menor de 35 años y el $82 \%$ estaba desocupado o realizaba trabajos informales al momento de la detención, trabajando en changas y trabajos temporarios. En relación con los datos educativos el SNEEP (2017) estableció que, de la población total, el 69\% tenía estudios primarios o inferiores al momento de ingresar al establecimiento. Al mismo tiempo, la situación 
educativa dentro de las unidades de detención era altamente precaria y escasa: el $56 \%$ no había participado de ningún programa educativo-formal durante el último año (SNEEP, 2017, p. 20-26).

La educación como derecho en su plano práctico (es decir, la gestión cotidiana de los espacios escolares dentro de las cárceles) es considerada un beneficio, regulado por un sistema de premios y castigos impartido por los agentes penitenciarios. De esta manera, acciones administrativas básicas para que las personas privadas de su libertad puedan acceder al espacio educativo son facilitadas u obstaculizadas por decisiones del personal penitenciario: la gestión de los cuerpos en lo que respecta al acceso a la escuela depende de su autorización. Gutiérrez (2010, p.145) advierte que cuando se habla de ciertos derechos de las personas privadas de su libertad como beneficios se está reduciendo al derecho a una función del tratamiento correccionalista, donde se otorga una recompensa positiva por una buena conducta. Este vocabulario del beneficio está presente en numerosa jurisprudencia que refiere, por ejemplo, al beneficio de la libertad condicional: pero la libertad condicional está regulada en el artículo 13 del Código Penal, en el que se establece que procede para los condenados con cierto porcentaje de la condena cumplida y bajo ciertas condiciones. Si es un derecho todos aquellos que cumplan con esas condiciones pueden ejercerlo, si es un beneficio dependerá de lo que considere la autoridad penitenciaria, los responsables del tratamiento penitenciario o el juez de ejecución, que pueden asignarlo conforme su parecer. Tal como establece este autor:

En contextos de encierro, la lucha actual no es solo por la ampliación de la oferta, el acceso y el ejercicio del derecho a la educación, sino por la construcción del sentido de educar en estos espacios específicos, más acá y más allá de la lógica del tratamiento regida por un sistema de premios y castigos que caracteriza a las instituciones de seguridad. En estos contextos, a los límites en el ejercicio efectivo del derecho a la educación, se suman tensiones y disputas propias del ámbito jurídico y penitenciario. (Gutiérrez, 2010, p. 133)

La posibilidad de gestionar la educación como un premio por parte de los agentes penitenciarios se vincula con las dificultades estructurales de garantizar el acceso a al cupo educativo para todas las personas que se encuentran privadas de su libertad. En la Unidad Penitenciaria dónde realicé mi investigación existían condiciones de sobrepoblación y hacinamiento que agravaban la situación de detención e imposibilitaban la garantía de derechos básicos como el acceso a la salud, la alimentación y la educación (Comité contra la tortura, 2018, p.180). Uno de los agentes penitenciarios encargado del Sector Escuela me explico en septiembre del 2017 que había en el sector masculino de esa unidad penitenciaria aproximadamente novecientas personas privadas de su libertad, mientras que la escuela sólo tenía tres aulas con una capacidad aproximada de treinta personas cada una y un aula más pequeña donde podían estudiar quince personas más. Es decir que entre la primaria que transcurría en el turno mañana y la secundaria que transcurría en el turno tarde sólo podrían asistir a la escuela doscientos diez estudiantes.

Por la complejidad expresada previamente los trabajos que han abordado el tema de la educación en cárceles han asumido generalmente una aproximación más prescriptiva que analítica, o bien se han centrado en propuestas de educación superior. No obstante, aunque los enfoques y objetos de indagación han sido en cierta medida diferentes, las investigaciones a las que me referiré a continuación han constituido importantes antecedentes para mi investigación.

Dentro de los estudios sobre educación y cárcel podemos identificar algunos trabajos que critican fuertemente el rol de la educación intramuros desde una lógica 
resocializadora y proponen que la misma se oriente a la garantía de los derechos humanos, para lo cual las escuelas deberían desplegarse como espacios abiertos en una institución cerrada (Bizarra, 2002; De Maeyer, 1997; Frejtman, 2008; Frejtman y Herrera, 2010; Manchado, 2012; Martel y Pérez Lalli, 2007; Salinas, 2002; Scarfó, 2006; Schneider, 2018).

Scarfó (2006) propone cuatro características fundamentales para garantizar el derecho a la educación intramuros, a las que ha denominado las 4A: accesibilidad, asequibilidad, adaptabilidad y aceptabilidad. Asimismo, ha construido estándares e indicadores sobre las condiciones de realización del derecho a la educación en las cárceles (Scarfó, 2011) con los que analiza los obstáculos vigentes en Argentina para garantizar el cumplimiento de este derecho (Scarfó y Zapata, 2013).

También existen diversas publicaciones y tesis que se focalizan en la relación entre cárcel y educación superior y en su mayoría describen proyectos académicos o de extensión universitaria de diferentes universidades argentinas. Algunos autores investigaron las motivaciones de los estudiantes en su ingreso y permanencia en el programa universitario de la Universidad Nacional de Córdoba (Acin y Mercado, 2006). Otros pensaron la articulación entre ambas instituciones en un sentido crítico (Manchado, Routier y Chiponi, 2019; Rodríguez, 2012; Sozzo, 2012) siendo múltiples las investigaciones que hacen referencia al Programa de extensión universitaria de la Universidad de Buenos Aires que existe desde 1985, denominado Proyecto UBA XXII (Calcagno y Cucut, 2012; Daroqui, 2000; Laferriere, 2006 y 2008; Parchuc, 2015; Pegoraro, 2012). Asimismo, varios trabajos se refirieren al Centro Universitario de la Universidad de San Martín (CUSAM), que existe desde el 2008 (Di Próspero, 2019; Lombraña, Strauss y Tejerina, 2017; Parziale, 2012; Perearnau, 2016).

Además de las mencionadas, dos investigaciones Berenstein (2014) y Tejerina (2016) fueron especialmente consideradas como antecedentes fundamentales de mi investigación ya que se realizaron en el mismo Complejo Penitenciario dónde realicé mi trabajo de campo e indagaron aspectos fundamentales de la educación en contextos de encierro. A partir de un relevamiento basado en entrevistas en profundidad, Berenstein (2014) analizó los sentidos que adquiría el vínculo pedagógico para diez alfabetizadores y cinco alfabetizandos que participaban del Proyecto de Alfabetización de Adultos en Contextos de Encierro implementado en dos Unidades Penitenciarias durante los años 2011 y 2012. Dado que en este Proyecto los alfabetizadores también se encontraban privados de su libertad, esta experiencia resulta el antecedente institucional más claro del Taller de Alfabetización en el que desarrollé mi investigación: se trata de una característica diferencial que, en diversas circunstancias, ha logrado sostenerse en este Complejo Penitenciario desde el año 2009.

Por su parte, Tejerina (2016) se propuso conocer los sentidos que los estudiantes del CUSAM le otorgan a la educación, así como a las vivencias de estudiar en una universidad que funciona dentro de una cárcel bonaerense. A través de entrevistas y observaciones participantes reconstruyó las trayectorias carcelarias de los estudiantes y su llegada al Centro Universitario, analizó cómo la lógica carcelaria atraviesa la experiencia universitaria y describió los sentidos que los estudiantes le otorgan a este espacio educativo en relación a las libertades que les permite alcanzar, los efectos que tiene en sus vínculos familiares y las modificaciones de sus percepciones respecto del manejo del tiempo intramuros y sus proyecciones de futuro.

Coincidiendo con Berenstein, el autor concluyó su investigación proponiendo que en los estudiantes del Centro Universitario de la Universidad de San Martín (CUSAM) se produce una transformación de su subjetividad (sobre todo en el caso de aquellos que 
viven en el pabellón universitario o transcurren en él su cotidianidad), modificándose la mirada sobre sí mismos y su posicionamiento respecto de la institución carcelaria. Tejerina además destaca su triple pertenencia institucional al CUSAM como investigador, interno y estudiante que implicó un fuerte proceso de reflexividad sostenido durante todo el proceso de su investigación.

Por lo expresado considero que el principal aporte de mi Tesis Doctoral (Pérez, 2020) a los estudios de educación y cárcel se vincula con el enfoque teórico-metodológico en la medida en que resultan escasos los estudios que hacen referencia a la vida cotidiana escolar en contextos de encierro.

\section{Objetivos}

El objetivo general de mi investigación fue comprender los alcances de las prácticas educativas que se desarrollaron dentro del Taller de alfabetización en su relación con un contexto institucional estructuralmente degradante donde predomina el control cotidiano de las personas privadas de su libertad.

En este artículo me propongo específicamente describir y analizar algunas prácticas cotidianas de organización de lo escolar, considerando los procesos de reflexividad y acompañamiento de diversas situaciones que permitieron a los y las participantes del taller resistir creativamente la vulneración cotidiana de sus derechos. Sostengo que las interacciones que se producen en el espacio escolar resultan una condensación y un reflejo de las relaciones que se viven en el resto del Penal (con otros compañeros/as y con otros/as agentes del Servicio Penitenciario). Mi pretensión entonces radica en documentar el modo en el que estos vínculos se expresaron en los procesos de enseñanza y aprendizaje que observé.

\section{El contexto socio-territorial del taller de alfabetización y sus actores sociales}

Durante el 2017 pude participar de una experiencia de alfabetización impulsada y llevada adelante por personas privadas de su libertad (en adelante los alfabetizadores), que estaba destinada a otros compañeros también privados de su libertad. La misma transcurrió en el contexto de una escuela mixta ubicada en la Unidad Penitenciaria 47 correspondiente al Complejo Penitenciario San Martín ${ }^{1}$. Este Complejo de tres unidades (46, 47 y 48) está ubicado en la localidad de José León Suárez correspondiente al Partido de San Martin en la Provincia de Buenos Aires. Comenzó a construirse en el 2006 sobre terrenos del CEAMSE (Coordinación Ecológica Área Metropolitana Sociedad del Estado), que se rellenaron con residuos para luego emplazar allí los edificios del Penal (Rancho Aparte, 2017; Tejerina, 2016, p. 35).

El Complejo Ambiental Norte III del CEAMSE es el principal depósito de residuos generados por la Ciudad Autónoma de Buenos Aires y el Conurbano Bonaerense. Las montañas de basura que cotidianamente se erigen en el predio generan dos tipos de trabajo, uno "oficial" a través de las nueve plantas sociales para la recuperación de los residuos que emplean a más de 700 personas, y otro "informal" que ha recibido los nombres de cirujeo de residuos y quema de los mismos en busca de metales. Esta práctica de supervivencia y sustento hace que diariamente ingresen a este lugar, alrededor de 800 personas en un horario restringido de entre treinta y sesenta minutos. La mitad de los trabajadores son mujeres y menores de edad que provienen de los

\footnotetext{
${ }^{1} \mathrm{Si}$ bien los nombres de las localidades y espacios institucionales se han mantenido con el propósito de contribuir a la documentación sociocultural del territorio, los nombres de los interlocutores se han modificado a fin de preservar su anonimato. Por un requerimiento editorial de la revista serán identificados por su participación en el taller como alfabetizadores, estudiantes y agentes penitenciarios y un número cardinal por su orden de aparición en el texto.
} 
barrios cercanos. (Carenzo, Acevedo y Bárbaro, 2012; Risler y Ares, 2013; Cubilla, 2015). El Complejo Penitenciario San Martín se visualiza como el horizonte de un conglomerado de barrios pobres y la vida cotidiana de vecinos y personas privadas de su libertad se desarrolla en un contexto de extrema precariedad donde las napas de agua se encuentran contaminadas, no hay redes cloacales, y se respira constantemente el olor nauseabundo que desprenden los gases contaminantes de los residuos (Risler y Ares, 2013, p.62-64).

El proyecto de alfabetización en el que se enmarcó este taller es una experiencia que surgió en los inicios del CUSAM (que funciona en la UP48), por la inquietud de un grupo de personas privadas de su libertad. En ese momento ellos solicitaron a la universidad adquirir herramientas para alfabetizar a sus compañeros que no sabían leer ni escribir. Como respuesta desde la Facultad de Humanidades de la UNSAM comenzaron a participar profesoras y estudiantes de la carrera de Psicopedagogía que, en encuentros semanales, brindaron herramientas didácticas al grupo de presos interesados. Luego la experiencia se hizo extensiva a las otras dos unidades penitenciarias del Complejo. El compromiso asumido por la universidad fue el de acompañar a los alfabetizadores en su proceso de enseñanza y aprendizaje, pero sin asistir a las clases de alfabetización forma permanente. En el 2017 la coordinadora del proyecto de alfabetización continuaba realizando este acompañamiento semanal en las tres Unidades Penitenciarias del Complejo hasta que en abril en la UP47 el Servicio Penitenciario exigió la presencia permanente de una docente universitaria en el taller. Esto habilitó mi participación en este espacio al que asistí todo el ciclo lectivo dos veces por semana (martes y viernes) durante tres horas. En la primera hora (de 11:00 a 12:00) nos reuníamos los seis alfabetizadores para planificar las clases y luego nos dividíamos en dos aulas. El taller transcurría en el horario de 12:00 a 14:00 para no superponerse con las clases de la escuela primaria y la secundaria.

Durante mi trabajo de campo tuve como interlocutores principales al equipo de alfabetizadores y a los más de 150 estudiantes que participaron de forma intermitente. También me vinculé con los y las agentes del Servicio Penitenciario Bonaerense que pertenecían al Sector Escuela. Y mantuve conversaciones informales con la directora de la escuela primaria que funciona en el complejo penitenciario, con la directora del centro universitario y con la coordinadora universitaria del proyecto de alfabetización.

\section{El enfoque etnográfico: observaciones participantes y entrevistas no dirigidas}

Guber (2012) propone la etnografía como un conjunto de actividades "abiertas" que permitirán al investigador priorizar la reconstrucción de las prácticas de los actores en el transcurso de su vida cotidiana, así como el sentido que los mismos le otorgan. Sus dos estrategias principales son la observación participante y las entrevistas etnográficas (o no dirigidas).

De acuerdo con esta autora antes de comenzar con las observaciones participantes, la actitud del investigador deber ser la de reconocer su (premeditada) ignorancia respecto de su objeto de conocimiento y su grado de participación estará vinculado a la situación que definió su acceso al campo de investigación. En mi caso dado que yo conocía a uno de los alfabetizadores (identificado como Alfabetizador Uno) por mis visitas al CUSAM ${ }^{2}$, rápidamente me sentí integrada al equipo docente y comenzamos a planificar conjuntamente las actividades. Conociendo además la trayectoria de esta experiencia intenté no intervenir en el aula desde el rol docente, o hacerlo lo menos posible. Como

\footnotetext{
${ }^{2}$ El centro universitario (CUSAM) funciona en la Unidad Penitenciaria 48 pero también pueden inscribirse estudiantes de las otras dos unidades penitenciarias del Complejo. El Alfabetizador 1 era estudiante de Sociología del CUSAM y participaba en los talleres extracurriculares de radio y teatro.
} 
señala Guber el frágil equilibrio entre observación y participación tiene que ver con la tensión, la flexibilidad y la apertura de la observación participante (2012, p.68). Hubo veces en las que regresé a mi casa pensando que había intervenido demasiado y en otras ocasiones pensé que no lo había hecho lo suficiente, sin embargo, siempre intenté privilegiar la consolidación del vínculo de confianza con el grupo en general y con los/las alfabetizadores y los/las agentes penitenciarios en particular.

Durante mi trabajo de campo no realicé entrevistas, aunque me ocupé de documentar diálogos, comentarios y anécdotas que transcurrían en las conversaciones cotidianas sostenidas por los actores sociales mencionados previamente. Distintos autores han señalado que la construcción de conocimiento etnográfico otorga un lugar central al lenguaje, entendido como un aspecto fundamental para la constitución del mundo social (Batallan y García, 1992; Guber 2012). La performatividad del lenguaje implica reconocer que en nuestras interacciones como sujetos sociales ejecutamos y producimos nuestra realidad otorgándole sentido a nuestras acciones. Desde esa perspectiva Guber recupera la noción de reflexividad como una de las propiedades del lenguaje que debe considerarse al hacer etnografía vigilando sus tres dimensiones: la reflexividad de los/las investigadores en tanto miembros de un colectivo cultural (y para esto se debe considerar la clase social, género, edad, afiliación política, etc.), la reflexividad de los/las investigadores en tanto integrantes de una comunidad académica (y esto supone revisar la perspectiva teórica, los habitus disciplinarios, las prenociones respecto del campo), y, por último, las reflexividades de sus interlocutores en la población que estudia (2012, p.46).

\section{Análisis de datos: la etnografía como texto}

Dos tipos de textos son fundamentales en el proceso de investigación de campo orientado antropológicamente: los registros de campo que ofician como documento, y la etnografía que es producto del proceso analítico. El registro es un recorte de aquello que el investigador supone relevante y significativo desde su propia perspectiva: se trata de documento que podrá ampliar cada vez más a medida que adquiera conocimiento técnico y del mundo particular que está reconstruyendo, pero en todo caso, en función de la minuciosidad pretendida, resulta clave su transcripción en un lapso no mayor a 24 horas (Rockwell, 2009, p. 60).

En mi ingreso al campo me propuse registrarlo todo (Rockwell, 2009, p. 62; Guber, 2012, p.102) aunque no tomaba nota durante las clases. No obstante, en el ejercicio de la reconstrucción inmediata pude recordar muchos más detalles de aquellos que creía percibir en la situación de observación/interacción. En este proceso me enfrenté en varias oportunidades a la reconstrucción de procesos dramáticos como descripciones de torturas, sanciones arbitrarias, secuencias de violencia verbal o física, y múltiples situaciones que en su evocación muchas veces me obligaron a interrumpir la redacción del registro y, hacia el final del proceso, prácticamente a evitar realizarlos (Pérez, 2019a).

Rockwell (2009) propone que luego de los primeros registros de campo, el investigador inicie su proceso de análisis a través de la escritura de descripciones analíticas intermedias. Esto permite, a través de una dinámica de retroalimentación constante entre la observación y el análisis, volver inteligibles un mayor número de relaciones conceptuales que den cuenta del orden particular, local y complejo del proceso estudiado. La autora sugiere cinco procedimientos analíticos pertinentes para transformar el material de registro: la interpretación, la reconstrucción, la contextualización, la contrastación y la explicitación (p.85). De acuerdo con Guber (2011, p.130) el texto etnográfico final es un argumento acerca de un grupo humano que 
supone una tesis y la construcción de los datos que la sostienen de forma coherente. En su escritura resulta necesario explicitar la lógica de la interpretación construida desde la reflexividad del investigador/autor. Si bien no realicé ese proceso analítico durante el año de mi trabajo de campo si pude destinar dos años de mi beca doctoral para la interpretación de los datos relevados.

A continuación, reconstruiré la descripción y el análisis de algunas escenas de mi trabajo de campo vinculadas a la organización espacial de los y las estudiantes en el aula del taller de alfabetización. La agrupación es uno de los elementos formativos de las experiencias escolares (Rockwell, 1986, p.7). Documentar las tensiones emergentes, mis aprendizajes y los mecanismos de resolución propuestos por alfabetizadores y estudiantes me permitirá demostrar la permeabilidad cotidiana del espacio educativo en relación con las violencias de un contexto carcelario estallado ${ }^{3}$.

\title{
La agrupación escolar intramuros: sus conflictos y resoluciones
}

Al permanecer en el taller durante varios meses pude notar que en la escuela confluía la conflictividad que estaba activa en otros lugares de la cárcel. Eventualmente los espacios educativos podían colaborar en la disminución de tales tensiones o agravarlas (por ejemplo, generando algún tipo de juego o competencia que, sin saberlo, permita exteriorizar allí los conflictos que traen de antes). La información respecto de los conflictos internos suele tenerla de manera privilegiada el personal penitenciario, por eso un profesor del CENS que funciona en el Complejo Penitenciario de Devoto, entrevistado en Suárez, Frejtman, López Chapato, Dávila, Bustelo y Fernández Valle (2012), afirma en función de su experiencia:

\begin{abstract}
Nosotros, los docentes, estamos siempre sujetos al trabajo que tengan los de requisa ${ }^{4}$, y si pueden o no bajar a los alumnos, porque son ellos los que manejan la cuestión de la seguridad. $\mathrm{Y}$ afortunadamente porque nosotros no entendemos nada de eso, no sabemos si A se puede juntar con el B, si C puede estar cerca de H. Dentro de una misma unidad residencial hay pabellones donde algunos presos no pueden estar juntos porque se matan. (p.78).
\end{abstract}

Por estar privados de su libertad los alfabetizadores conocían a los y las estudiantes y en general intuían sus causas delictivas porque identificaban su pabellón de procedencia. Esto les permitía conocer la estrategia de selectividad que utilizaba el personal penitenciario y, durante el ciclo lectivo 2017, plantear diversas estrategias para ampliar la accesibilidad a la escolaridad de otras personas privadas de su libertad. En este sentido, la clasificación de los pabellones que describe Ángel (2015) estuvo constantemente presente durante mi trabajo de campo y su estructura permite explicar, en parte, la lógica de algunas tensiones que acontecieron en el espacio del taller. Este autor reconstruye las representaciones estereotipadas y polarizadas del universo carcelario donde por un lado se encuentran los chorros, que se alojan en los llamados pabellones de población (donde están los chorros y los pibes buenos ${ }^{5}$ ) y por otro lado están los giles (que incluyen al colectivo de los violines ${ }^{6}$ ) quienes se alojan en otros pabellones, algunos de ellos cristianos (2015 p. 22-29). Los primeros tienen mayor jerarquía y su denominación, además de vincularse con la causa delictiva, se asocia a los conceptos de: hombría de bien, fidelidad, destreza, valentía y virilidad (Ángel, 2015,

\footnotetext{
${ }^{3}$ Esta es una categoría nativa que algunos alfabetizadores utilizaban con frecuencia para explicarme que el nivel de conflictividad interna de la UP47 era muy elevado

${ }^{4}$ Se refriere a los agentes penitenciarios, que en ese Penal revisan a los estudiantes antes de bajarlos a la escuela.

${ }^{5}$ Este un término utilizado en la cárcel para referirse a aquellos individuos que son buenos porque se la bancan contra la policía, como así también dentro de los pabellones. Además, son chorros y no dudan en tener que pelear con cualquiera. Muchas veces se puede observar dentro de los pabellones que cuando hay conflicto gritan con una faca en la mano: "yo no soy un gil, soy un pibe bueno y re peleo no se confundan" (Ángel 2015, p.59).

${ }^{6}$ Es una categoría nativa para designar a los internos que estaban presos por violación.
} 
p.23). Por el contrario, los giles son los ladrones ocasionales que dentro de la cárcel viven oprimidos (Maduri 2015, p.80), o aquellas personas con causas relacionadas con drogas o por haber cometido un homicidio que no haya sido en un hecho delictivo. Son los más quedados y poco luchadores, los que dentro de la cárcel no hacen ningún tipo de reclamo. El término gil designa todo lo contrario de chorro, es decir: malicia, infidelidad, inaptitud, cobardía y debilidad (Ángel, 2015, p.26).

\section{Los pabellones de población: entre la conducta y el ritmo}

En las reuniones de planificación que realizábamos antes de la clase por lo general los alfabetizadores me ponían al tanto respecto de qué pabellones estaban engomados (castigados) esa semana, lo que permitía anticipar que esos estudiantes no bajarían al taller. Ya desde mis primeras visitas, cuando le pregunté respecto de las causas de los engomes, el Alfabetizador Uno explicitó la situación de tensión que se vivía en el Sector Masculino del penal, ya que: allí solamente había cuatro pabellones de población. Con esta afirmación, él me quiso decir que los otros seis pabellones eran de giles, cuestión que resultaba problemática ya que, si bien en ese Penal los chorros eran minoría en la distribución de los pabellones, eran mayoría en cantidad de personas. Esta situación implicaba que estos sectores, donde los presos de población compartían alojamiento y convivencia, estuvieran constantemente superpoblados o con una alta rotación de personas (algunos jóvenes eran ingresados inicialmente a alguno de los pabellones de giles, pero luego, cuando comprendían esta situación, solicitaban el pase a un pabellón de población. Sin embargo, el único que accedía a recibirlos era el Pabellón 7 dónde los niveles de violencia eran muy elevados, por ese motivo los jóvenes volvían a pedir el cambio a alguno de los pabellones de "giles").

Según el Alfabetizador Uno, los encargados de los otros pabellones de población (el uno y el dos) por ser pabellones de conducta ${ }^{7}$ intentaban restringir el acceso a personas provenientes del Pabellón ATR (A Todo Ritmo, Pabellón 7), y otros jóvenes alojados en los pabellones de giles, dejando ingresar solamente a que quisieran rescatarse con la cultura (es decir que pudieran regular el consumo de drogas) y hacer conducta para salir del Penal, lo que implicaba que no tuvieran actitudes violentas hacía sus compañeros ni anduvieran enfierrados. Pero dejar el ritmo era una decisión que implicaba hacer un clic respecto de determinadas prácticas carcelarias. Significaba querer desmarcarse de la posición de ser reconocido como un pibe bueno. Tejerina (2016) se refiere a este tipo de pabellones de población y su articulación con los espacios educativos:

En este pabellón (de población) se presenta un gran dilema sobre participar asiduamente en las prácticas educativas y estar en el pabellón "curtiendo el mambo" ${ }^{\text {, fumando unos }}$ porros, tomando algunos "bártulos"9 escuchando música o haciendo gimnasia. Los que conviven en esos pabellones, saben que ir a la escuela o estudiar es por un beneficio para acercarse a su libertad, pero no muchas veces esto es entendido por los "chorros" o "pibes buenos" (p. 18)

Ángel en su investigación coincide con esta idea, sosteniendo que para los jóvenes alojados en los pabellones de cachivaches (o $A T R$ ), la creencia en la carencia de

\footnotetext{
${ }^{7}$ Los pabellones de población se dividían en pabellones de conducta o pabellones de cachivaches o ATR. Quienes integraban los primeros intentaban sumar "buena conducta" para avanzar en la progresividad de la pena establecida por la Ley 24660/96. Quienes convivían en el pabellón ATR eran muy jóvenes y confirmaban que la vida cotidiana allí era peligrosa pero entretenida. De acuerdo con lo que me decían los alfabetizadores, en el Pabellón siete era en el que más corría la droga.

${ }^{8}$ Esta denominación se refiere a las diferentes actividades que se desarrollan dentro del pabellón de población, donde tanto el consumo de drogas como las actividades físicas para las resistencias de las peleas son parte de la cultura de las personas privadas de libertad que engloba un patrón de conducta (Tejerina 2016, p.18).

${ }^{9}$ Se refiere a psicofármacos que pueden ingresar desde el exterior o puede brindarlo el sector de sanidad, a aquellos internos que están medicados u otros que se medican sin estarlo.

(Tejerina 2016, p.18).
} 
competencias y conocimientos personales para obtener un lugar en el espacio educativo o laboral intramuros los habilita a probar otras opciones de supervivencia (2015, p.42). Esta posición se acentúa si la escuela, además, es vista como el espacio habitualmente destinado para los giles y los violines por ser quienes presentan un mejor comportamiento de acuerdo con la mirada de los agentes penitenciarios (Pérez, 2020, p.122).

La apuesta del Alfabetizador Uno, a la que adherían los otros alfabetizadores, coincidía con estos diagnósticos de las investigaciones mencionadas; por este motivo su objetivo era sumar al taller de alfabetización la mayor cantidad posible de jóvenes. Aunque se reconocieran como pibes chorros o jóvenes alojados en los pabellones de giles, para que se apropiaran de ese espacio y comprendieran que la lógica tumbera (asociada a las drogas y a las peleas) los dejaría "atrapados" en el sistema carcelario. En cierta medida, esta iniciativa de los alfabetizadores dio resultado: ya que más allá de los engomes semanales, tuvimos una buena cantidad de estudiantes del Pabellón 7 y aunque había mucha rotación en el Penal, en general asistían mayoritariamente estudiantes jóvenes.

\section{Los pabellones de los "giles"}

Dentro del otro conjunto de pabellones "los de giles", identifiqué el Pabellón 4 que era denominado cristiano y otros pabellones como el 5, el 6, el 9 y el 10 que parecían ser pabellones con población heterogénea: de ellos provenían principalmente jóvenes menores de 25 años y en pocos casos estudiantes adultos.

Del Pabellón cristiano solo hubo un estudiante (identificado como Estudiante Uno), que mantuvo su asistencia a clases de modo constante durante todo el ciclo lectivo. Otros estudiantes del mismo pabellón participaron de forma eventual en algunas clases, y algunos trabajaban en otra de las aulas con la Alfabetizadora Dos, el Alfabetizador Tres y el Alfabetizador Cuatro. Los violines que venían al taller de alfabetización pertenecían, según el Alfabetizador Uno, principalmente a este pabellón. De acuerdo con la descripción de Ángel, los pabellones cristianos se caracterizan por introducir determinados dispositivos culturales del pentecostalismo (sus narrativas, su ritualidad, su estructura de liderazgos) para mantener el control en el espacio de convivencia y reducir los niveles de violencia intracarcelaria (2015, p. 44).

Además de los jóvenes alojados en el pabellón 7 (ATR), también participaban del taller de alfabetización otros jóvenes de menos de veinticinco años que, en el transcurso del año fueron cambiando de lugar de alojamiento (algunos se sumaron al Pabellón 7 y otros rotaron entre los otros pabellones de giles).

De acuerdo con lo que informa el sitio web del Servicio Penitenciario Bonaerense, en el Pabellón 10 de la UP47 se aloja a detenidos de entre 18 y 21 años porque allí funciona el Programa Integral de jóvenes y Adultos, donde aprenden pautas de convivencia y autogestión, editan una revista y participan de actividades laborales y culturales". Sim embargo, durante mi trabajo de campo esto no se verificaba en modo alguno, sino que los jóvenes de esa edad circulaban entre varios pabellones y de modo constante. De todos los jóvenes que participaron del taller y no estaban alojados en el Pabellón 7, sólo uno mantuvo su asistencia a las clases durante todo el ciclo lectivo: el Estudiante Dos. En el resto de los jóvenes hubo mucha intermitencia entre altas y bajas. La gestión de estos pabellones parecía ser confusa: no fueron definidos como cristianos y tampoco reunían las características de los pabellones de población. Parecía más bien que la configuración de estos pabellones cambiaba constantemente al ritmo que lo hacía la población carcelaria. 


\section{La distribución de los estudiantes en el aula y la agrupación forzada}

Durante los años que llevo investigando este tema, varias personas me preguntaron cómo llegué a conocer las causas delictivas de los estudiantes, o por qué estaba interesada en conocer "ese" dato. A esta inquietud yo respondía que esa información nunca había sido requerida por mí de modo explícito, pero que era un dato que emergía del campo porque en cierta medida regulaba las interacciones que se producían en el taller de alfabetización. Si bien nunca indagué voluntariamente la causa delictiva de los estudiantes del taller, me daba cuenta de que sabiendo el pabellón de procedencia y la edad aproximada podía tener una idea intuitiva de las relaciones que iban a establecer en la clase. Esta información sí era conocida por todos los/as estudiantes, los/as alfabetizadores y los/as agentes penitenciarios, y por lo tanto resultaba fundamental para entender los mecanismos de agrupación en el aula (Rockwell, 1986, p.7), así como los motivos de algunas situaciones de tensión.

A la complejidad descripta en los apartados anteriores respecto de las clasificaciones internas de los pabellones, se sumaba que el taller era mixto y esto condesaba cierta tensión sexual sobre todo entre los y las jóvenes, que por ejemplo se sentaban con sus parejas y se besaban varias veces durante el transcurso de la clase o directamente estaban abrazados o tomados de la mano durante las dos horas del taller. Este era el único momento, a excepción de las visitas (si es que las tenían), donde podían verse varones y mujeres.

La agrupación de los estudiantes en el aula se correspondía con la información que ellos manejaban respecto de sus causas, sus pabellones de procedencia y sus edades. En los cinco bancos dobles del ala izquierda (la fila 1) se sentaban siempre las mujeres jóvenes (menores de 30 años) y eventualmente en los últimos asientos de esa misma fila algunas de ellas con sus parejas (varones jóvenes). En la fila siguiente (fila 2) se sentaban otros jóvenes varones de distintos pabellones (el 8, el 9, el 10) y al fondo los jóvenes del Pabellón 7 con algunas de sus parejas (mujeres jóvenes). En la fila de bancos de la siguiente fila (fila 3 ) se sentaban los estudiantes que venían a clase por primera vez a excepción del estudiante dos (que venía del pabellón 10). Él siempre se sentaba solo en el primer banco de la tercera fila y permanecía toda la clase muy atento y participando activamente. Recién en el último mes comenzó a sentarse con otros jóvenes de los pabellones 8 y 9 en el primer asiento de la fila 2.

En la última fila (la 4) que daba a la ventana del aula se sentaban los varones adultos del Pabellón 4 y excepcionalmente una mujer de más de 45 años, la Estudiante Tres.

El gráfico que presento a continuación es un intento de construir una imagen estable de una distribución que, en realidad, siempre fue dinámica. Lo que me interesa destacar es que las y los estudiantes jóvenes que participaban del taller de forma más estable nunca se acercaban a la fila 4, donde la Estudiante Tres y el Estudiante Uno mantuvieron su misma ubicación durante todo el año. Los jóvenes no tenían problemas de trabajar en grupo entre ellos, o inclusive de mezclarse entre sí (con las mujeres o con jóvenes de otros pabellones $(7,8,9$ y 10$)$. Pero no se acercaban a trabajar con la Estudiante Tres ni con los varones adultos del Pabellón 4. 

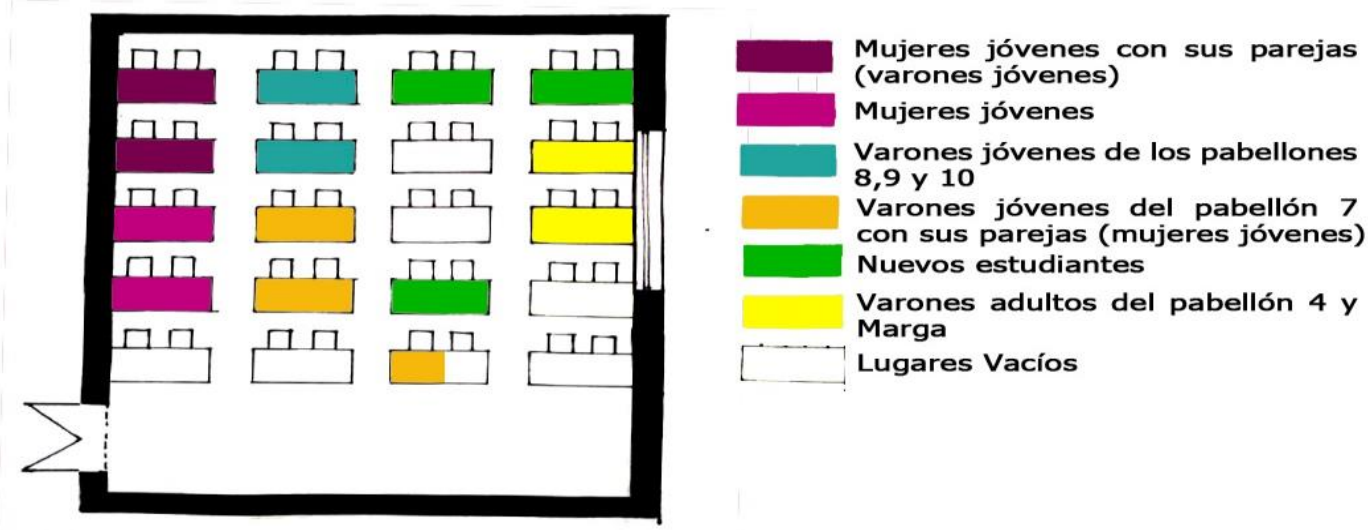

Gráfico 1: Distribución de los estudiantes en el aula del Taller de alfabetización

A continuación, me referiré a una situación de campo que permite desplegar las tensiones e incomodidades que surgieron en el aula cuando, por desconocer esta configuración forcé el trabajo en grupos mezclados de estudiantes.

\section{El día de la agrupación forzada}

El martes 9 de mayo llegué media hora antes de la clase y solamente estaba el Alfabetizador Tres, en el aula donde nos reuníamos para preparar la clase. Como el resto de los alfabetizadores no podría venir le propuse que dividiéramos al aula en dos grupos y trabajáramos distintas actividades con cada uno, luego podríamos cambiar y finalmente hacer una puesta en común. Él estuvo de acuerdo y comenzamos a revisar los manuales de primaria que teníamos a mano.

Además, tenía la Revista YO SOY ${ }^{10}$, editada por la Organización Social Yo No Fui, que en su contratapa tenía una publicidad del INADI que decía LA PALABRA TE LIBERA. Le propuse al alfabetizador Tres que uno de los grupos podía debatir respecto de esa oración, él se entusiasmó en comenzar con esa actividad. Para otro grupo pensamos trabajar con un mapa de Argentina, que pudieran verlo e identificar los lugares que conocían, las regiones del país, contar anécdotas de su pasado o de sus vacaciones en alguna provincia, ese grupo comenzaría conmigo. Como finalmente se sumó la Alfabetizadora Dos, a la reunión de planificación, armamos un tercer grupo que ella coordinaría en el que conversarían sobre las fechas patrias. Ese día vinieron aproximadamente veinticinco estudiantes y trabajamos todos en la misma aula, por lo tanto, había algunos estudiantes que sabían leer y escribir, y otros que lo hacían con dificultad.

Cuando se armaron los grupos, yo quedé encargada del ala derecha con los varones adultos, y les pedí a un grupo de jóvenes que se sumará con nosotros. Lo hice porque por mi experiencia como docente de adultos estaba muy convencida de la potencia del trabajo grupal heterogéneo, aunque sabía que los estudiantes se resistían, al menos inicialmente, a trabajar en grupos armados por el profesor.

\footnotetext{
${ }^{10}$ Su realización es impulsada por el Colectivo Editorial Tinta Revuelta conformado en el taller de escritura y periodismo de Yo No Fui que es una organización social que trabaja desde el año 2004 en proyectos de formación en artes y oficios en cárceles de mujeres (federales y de la Provincia de Buenos Aires) y en el medio libre, una vez que las mujeres recuperan su libertad.
} 
Efectivamente los jóvenes al principio se negaron (dijeron que preferían trabajar solos), pero yo les insistí y finalmente accedieron, aunque en el transcurso de la clase los noté muy incómodos. Al considerar las estructuras de participación (Rockwell, 1986, p.9) generadas en el grupo, las diferencias de procedencia y edad de los asistentes al taller de alfabetización previamente descriptas permitían entender lo acontecido.

Por un lado, dos de los jóvenes buscaron todo el tiempo recibir mi atención, me preguntaron de que barrio venía, si había viajado, cuáles eran mis actividades en la calle, etc. Se trataba del Estudiante 4 y el estudiante 5, quienes tenían muchas dificultades para escribir y cuando no atendía a sus requerimientos se dispersaban muy rápidamente. Pero a pesar de eso los noté particularmente incómodos.

Por otro lado, uno de los adultos, el Estudiante Seis tenía aproximadamente 45 años y por una situación de salud su capacidad de audición estaba disminuida. Por este motivo y para hacer un chiste al respecto uno de los jóvenes, que tenía aproximadamente 21 años, dijo en voz alta: la sordera del Estudiante 6 se cura con una buena limpieza de oídos. Enseguida los otros jóvenes se rieron y el otro adulto del grupo, el Estudiante 7, de aproximadamente 42 años, les respondió (mientras me miraba): Que había que tener paciencia con el Estudiante 6 y que ellos no podían ser tan irrespetuosos con su compañero. A los jóvenes no pareció importarles su apreciación, yo no dije nada al respecto porque el Estudiante 6 no le había dado importancia al comentario, y seguí con la conversación propuesta en la actividad.

Unos minutos más tarde, el Estudiante 5, que también exhibía cierta resistencia en las interacciones con los estudiantes 6 y 7, comenzó a gritar: Acá en el fondo estamos los pibes jóvenes, jlos mejores nos ponemos en el fondo! Yo no entendía a lo que se refería, así que solamente lo miré y me reí por su arrebato. Él también se rio y seguimos conversando grupalmente sobre el tema de la actividad (que ese momento había derivado en la identificación de los puntos cardinales).

En ese momento no comprendía bien porque sentía cierto nerviosismo entre los estudiantes jóvenes, aunque intuía que tenía que ver con las causas penales y los pabellones donde se encontraban alojados, por lo que a la clase siguiente lo conversé con el Alfabetizador 1 . Él confirmó que los estudiantes 6 y 7 eran violines y que por eso los jóvenes estaban incómodos. A él también le molestaba su presencia en el aula, pero: lo teníamos que manejar porque era decisión del Servicio Penitenciario que vinieran. Desde ese día no volví a forzar el armado de grupos, y siempre que los estudiantes trabajaron de ese modo se reunieron de acuerdo con su voluntad y en general, coincidiendo con la distribución que tenían en el aula. Este importante aprendizaje situado (Lave y Wenger, 1991, p.4) tuvo que ver como mi implicación como alfabetizadora, que supuso la observación y la atención de las interacciones entre los estudiantes y con el contexto específico en el que se desarrolló la actividad (el aula de la cárcel). Sin embargo, para mí fue muy importante tener la confianza suficiente como para confirmar esta información con el Alfabetizador 1, quién realmente conocía como funcionaban las clasificaciones y los estereotipos dentro del Penal y siempre se mostraba muy bien predispuesto a acompañar mis "frustrantes descubrimientos".

\section{Cuando el ritmo también llega a la escuela}

Otro ejemplo vinculado a la permeabilidad del espacio educativo en relación con el contexto carcelario sucedió el viernes 11 de agosto. Cuando llegué a la reunión de planificación, el Alfabetizador 1 y la Alfabetizadora 2, me contaron que el clima en la escuela estaba muy tenso porque había ocurrido un incidente en la secundaria. La 
Alfabetizadora Dos había presenciado el conflicto porque estaba en el aula como estudiante (de tercer año) y lo describió de este modo:

La docente de informática estaba intentando dar clases (sin computadoras disponibles para tal fin puesto que no hay ningún aula con máquinas) y nos había dividido en grupos con una consigna. Pero algunos estudiantes estaban en cualquiera, hacían mucho quilombo y se mataban de risa. Cuando ella intentó poner límites y pedirles que trabajen una de las pibas saltó y le dijo: -Mira, no nos rompas las pelotas porque no vamos a hacer nada, dejános tranquilos que estamos acá con nuestro rancho ${ }^{11}$. ¿Por qué no te vas a tomar mate con los otros profes a la sala de profesores?

La pibita estaba muy zarpada y yo vi como a la profe se le puso toda la cara roja porque se sintió desbordada. Después de eso se dirigió a hablar con la preceptora (que era la máxima autoridad de la escuela presente en el edificio). Y más tarde durante del recreo parece que encontraron a algunos estudiantes compartiendo un porro y cuando los penitenciarios los fueron a buscar varios de ellos hasta se enojaron exigiendo que en el recreo los dejaran tranquilos. Está todo mal, están re zarpados los pibes". (Registro de campo, viernes 11 de agosto del 2017)

Ambas situaciones llevaron a que los agentes penitenciarios, la preceptora y los y las docentes de secundaria decidieran levantar las clases de ese día. Tal como lo define Rockwell, si bien existe una estructura básica de participación en la escuela que supone que el docente inicia, dirige y controla las interacciones con los estudiantes, la transmisión de conocimientos supone una negociación constante (1986, p.10).

En ese sentido, al escuchar lo que había sucedido con la profesora de informática me di cuenta la enorme diferencia que significaba en mi caso, que también venía de afuera, contar con las reuniones de planificación donde tenía la posibilidad de trabajar en un equipo pedagógico con los alfabetizadores en su rol de docentes presos: de esta manera, podíamos adecuar la estructura de participación habitual a partir de una anticipación del estado en que llegarían los estudiantes, y planificar juntos ciertas actividades $u$ organizaciones de la clase que tuvieran en cuenta los deseos y necesidades de los y las estudiantes. En el caso de la docente de informática, el desconocimiento de este estado de ánimo y la imposición de una estructura de participación convencional parecía haber intensificado un conflicto que, por lo que pude reconstruir, la mayoría de las veces provenía más bien de situaciones extra-clase, pero se manifestaba también allí.

Pero, además, los alfabetizadores imponían respeto en el aula como docentes, pero también como presos, y probablemente por este motivo, las estructuras de interacción propias de la clase podían negociarse y fluir sin mayores contratiempos. Aunque algún estudiante hubiera llegado tensionado por un conflicto previo en los pabellones, nunca vivimos en el aula situaciones en las que ellos desafiaran nuestra autoridad de modo violento. Efectivamente hubo algunos contrapuntos que los estudiantes señalaban respecto de los contenidos, pero estas diferencias se expusieron sin agresión; de hecho, con los alfabetizadores buscábamos propiciar las discusiones y los debates.

Por estas características, si bien el Penal era un espacio donde la violencia se expresaba de múltiples maneras en los pabellones, el espacio del taller reunía dos condiciones que permitían evitarla: cierta paridad dada por los talleristas que compartían la situación de privación de la libertad (lo que lo distinguía de, por ejemplo, la escuela

\footnotetext{
${ }^{11}$ Maduri (2015, p.82) define rancho como: grupo de pertenencia dentro de la cárcel que se fortalece según vayan sobreviviendo. Sinónimo de amistad. Ferreccio (2017, p.379) agrega: es el nombre que recibe la comida que suministra la administración penitenciaria, pero es también el nombre que tienen los grupos que la comparten. De hecho, los pabellones y el dominio al interior de estos, se encuentra organizado en ranchos. Aquel que por diversas razones no consigue entrar a un rancho es un "paria".
} 
secundaria), pero a la vez cierta especificidad dada por el espacio que era reconocido por los asistentes como distintivo del resto de los momentos compartidos con pares dentro del Penal porque les proporcionaba una posibilidad de aprender otras cosas (a como el espacio de alfabetización jurídica de los viernes dónde aprendían a "lidiar con la justicia", a tramitar situaciones de violencia y sufrimiento como la actividad de escritura catártica, a improvisar un programa de radio, etc.). El diálogo propiciado y fomentado en el taller fue un aspecto fundamental del aprendizaje que allí tenía lugar, aun cuando la estructura de participación fuera "en esencia" la convencional.

La irrupción del "ritmo" dentro de la escuela constituye un acontecimiento que puede explicarse en gran medida por las dinámicas propias del penal, y su procesamiento también se vincula con ellas. En la situación narrada aquí, una vez que el Agente Penitenciario Uno (responsable de la escuela) identificó a los estudiantes implicados en los conflictos generados en la clase de informática y en el recreo, fueron excluidos de la lista de asistencia a la secundaria. De acuerdo con la explicación de la Alfabetizadora 2 ya no podrían bajar más por sus problemas de conducta:

Los pibes y las pibas que armaron el bardo no van a venir más porque estaban muy zarpados y el Agente Penitenciario 1 anotó sus nombres. Justo hoy la Agente Penitenciaria 2 me preguntó qué opinaba yo de este tema porque parece que encontraron como veinte porros.

¡iiAhhh, es un montón!!! ¿Pero estaban muy drogados?

No. Pero el tema es que ahora empezaron a decir que quieren cerrar la escuela y eso es un problema porque vamos a tener que pagar todas las consecuencias por el bardo de algunos. (Registro de campo, viernes 11 de agosto del 2017).

Frente a esta situación de conflicto ocurrida en la escuela secundaria, decidimos que el Alfabetizador 1 y la Alfabetizadora 2 comenzarán la clase del taller hablando sobre este tema, como un mecanismo para posibilitar el debate. Queríamos dar nuestro punto de vista y también comprender la mirada que tenían los y las estudiantes sobre la situación. La idea era conversar sobre el valor de la educación, pero agregando a la discusión los límites institucionales en relación con el consumo de drogas, específicamente sobre las amenazas de los penitenciarios respecto de su voluntad de cerrar el espacio educativo - restringir su acceso únicamente a quienes demostraban un comportamiento adecuado.

Por este motivo, ese día en lugar de separar los grupos en dos aulas como hacíamos habitualmente, les pedimos que se concentren en una de ellas, que resultó colmada en su capacidad. Había más de sesenta estudiantes. La Alfabetizadora Dos comenzó hablando de lo que había pasado el día anterior en la secundaria y agregó:

A mí me llevó más de un año y muchos escritos judiciales que me dieran un cupo en la escuela. Porque atrás de ustedes hay cuarenta más esperando entrar, entonces no desaprovechen esta oportunidad. Cuiden la silla donde ponen el culo porque yo soy rea como ustedes y por eso se los digo, siempre todo con respeto. Nos cuidamos entre nosotros y respetamos a los docentes también. (Registro de campo, viernes 11 de agosto del 2017)

Su señalamiento sobre el aprovechamiento del cupo escolar es relevante ya que el acontecimiento en la clase de informática demostraba que la permanencia de los estudiantes en las aulas no estaba garantizada. Como muestra la joven estudiante de secundaria, haber accedido a un cupo en la escuela dependía de múltiples factores y ocupar una silla no era sinónimo de haber aprendido cómo conservarla. Luego de la 
intervención de la Alfabetizadora 2, el Alfabetizador 1 también expresó su punto de vista respecto del conflicto inherente a la cárcel y la amenaza que constituía para la continuidad del espacio educativo:

Los profesores vienen de la calle y ya por eso merecen nuestro respeto, hay un montón de gente que no quiere venir a enseñar acá, a la cárcel ¿se dan cuenta de eso? Obviamente que cualquiera puede tener un mal día, eso se entiende por todo lo que está aconteciendo acá, pero por eso es importante poder venir a la escuela. Si seguimos así vamos a lograr que la gorra ${ }^{12}$ se meta adentro del aula y no queremos eso (Registro de campo, viernes 11 de agosto del 2017).

Mientras ambos hablaban el clima del aula era de absoluto silencio, algunos estudiantes asentían con sus cabezas y otros afirmaban en voz alta ; Es verdad eso! En un momento el alfabetizador les preguntó: ¿Ustedes para qué vienen a estudiar? ¿Vienen por el beneficio? Los estudiantes no respondieron, probablemente porque parecía una pregunta retórica a la que ya estaban habituados, propia de las estructuras de participación escolar mencionadas previamente (Rockwell, 1986, p.9), tras lo cual él agregó:

Los jueces nos exigen que estudiemos y trabajemos, pero yo creo que son ellos (los jueces) los que están mal porque eso no se puede (entiendo que se refería a falta de cupo y al modo de gestionarlo por parte del Servicio Penitenciario Bonaerense). Para el poder jurídico todos nosotros somos un número y la educación es lo que los va a llevar a la puerta (de salida del Penal) porque es lo primero que piden los jueces. (Registro de campo, viernes 11 de agosto del 2017).

Esta intervención demostraba cómo este espacio educativo implicaba aprendizajes sobre la gestión del cupo educativo y el manejo de los conflictos intramuros tanto para los alfabetizadores como para los y las estudiantes.

En este sentido, mientras el Alfabetizador 1 hablaba yo anoté en el pizarrón a modo de síntesis: ¿ Para que venimos a estudiar? Y comencé a escribir a modo de punteo algunas de las apreciaciones del alfabetizador: Por el beneficio para avanzar en la progresividad de la pena. Pero cuando retomé esta pregunta frente al aula, Una estudiante agregó: para descolgar de los problemas. A lo que la Estudiante 3 añadió: ;Si, y también por el beneficio personal de aprender! Y otro estudiante sumó: Para hacer amigos y amigas. De esta manera, las intervenciones de los estudiantes sumaron otros motivos a la lógica del beneficio que había sido evocada por el Alfabetizador 1 en su pregunta retórica.

A raíz del suceso que describí previamente, también la secundaria procuró trabajar sobre el conflicto en posteriores encuentros con sus estudiantes: armaron para ello una jornada de compromiso educativo dónde los y las estudiantes escribieron lo que representaba la educación secundaria para ellos, y a lo que se comprometían para que el espacio escolar continuara funcionando. Luego pegaron esas hojas en unos afiches que colgaron en las paredes del aula en la que dábamos clases con el Alfabetizador 1 y el Alfabetizador 3.

Algunas clases después e inspirado por estos escritos, el martes 12 de septiembre el Alfabetizador 1, nos sugirió trabajar con esta idea en nuestras clases. Les propuso a los y las estudiantes que escribieran qué significaba este espacio educativo para ellos/as y a qué se comprometían para cuidarlo. Sus producciones me permiten profundizar en estas ideas sobre el aprendizaje de la gestión de los conflictos en el taller de alfabetización. Transcribo a continuación cuatro escritos, uno de un estudiante del

\footnotetext{
${ }^{12}$ Se refiere al Servicio Penitenciario Bonaerense.
} 
Pabellón 7 (el Estudiante 8), otro del Estudiante 1 del Pabellón 4, otro del Estudiante 2 del Pabellón 8 y uno de una estudiante alojada en el anexo femenino (Estudiante 9).

El estudiante 8 del Pabellón 7, escribió:

El compromiso educativo se trata de recibirlo para poder darlo como a compañeros al igual que a nuestra familia. Cuando una persona se compromete a algo se trata de poner en la mente ese punto al cual querés llegar para lograr el objetivo. Y la educación se trata de ser respetuosos con los docentes, los compañeros y el Servicio Penitenciario Bonaerense y así poder lograr mi meta educativa en la vida. La educación me está dando entendimiento de cosas que no entendía y hoy entiendo que la educación es una herramienta útil para abrir puertas en todos los ámbitos.

Este estudiante que venía del Pabellón 7, parecía haber entendido "todo" lo que procuraban transmitir los alfabetizadores. La motivación principal del Alfabetizador 1 de incluir a estos jóvenes del Pabellón ATR en las aulas, pero sobre todo de que encontrarán motivos para quedarse, parecía cumplirse en este caso. El primer clic que este alfabetizador quería que hicieran los jóvenes que venían al taller era precisamente este, el concebir la educación como una herramienta reflexiva, que además de abrirles la cabeza, les abriría puertas (comenzando por la salida del Penal).

Por su parte, el Estudiante 1 del Pabellón 4, escribió:

El compromiso educativo es algo muy personal porque uno se compromete a escuchar, a respetar, a aprender y a socializarse con personas diferentes o culturas diferentes sin discriminar. Especialmente el espacio que es alfabetización que nos permite ingresar sin discriminar religión, raza o color de piel.

Personalmente doy gracias a este espacio y a las personas que dedican su tiempo a enseñarnos y también porque me ayudó a salir de un pozo en el cual estaba hundido. Gracias a este espacio conocí personas que jamás pensé conocer y de muy buen corazón. Por eso digo que es personal y que cada uno pensamos diferente. ¡GRACIAS!

El texto del Estudiante 1 resulta interesante por lo que no se animó a decir pero que se deja ver, que es su agradecimiento al taller de alfabetización por no discriminarlo, a pesar de su causa penal por violación. Si bien es verdad, que él fue el único estudiante que permaneció de ese pabellón (quizás los demás asistentes se sintieron incómodos entre tantos jóvenes), también es cierto que, aunque todos tuviéramos esta información, en ninguna oportunidad durante el ciclo 2017 tuvo que enfrentar una situación de ataque personal (como el "chiste" que mencioné previamente dirigido hacia el Estudiante 6). En general todas las intervenciones del Estudiante 1 eran escuchadas con respeto y el resto de los compañeros lo trataba con alguna distancia, pero sin manifiesta hostilidad.

El estudiante 2 del Pabellón 8, escribió:

El compromiso con la educación para mí es tener constancia y respeto con el espacio que nos resguarda y apoya para tener un desarrollo tanto personal como académico. Esto nos permite tener valores personales a través del aprendizaje. Nuestra cultura crece facilitando nuestra capacidad para tener una mayor conciencia y respeto con lo que logramos tener. El aprendizaje es algo que nadie nos puede sacar porque es un derecho que nos hace libres, aunque estemos encerrados.

Él parecía haber comprendido el sentido de derecho a la educación, sin que nos hubiéramos referido a ello de ese modo o al menos no de manera intencional en este espacio hasta ese momento. En ese sentido su texto daba cuenta de su profunda apropiación de esta experiencia formativa. 
Finalmente, la Estudiante 9 alojada en el anexo femenino, escribió:

\begin{abstract}
Nos comprometemos a concurrir al espacio educativo y respetar las normas que exija el establecimiento teniendo en cuenta que estamos detenidos y este espacio se debe respetar. Porque más allá de que haya gente de la calle podemos aprender muchas cosas buenas que en un futuro nos pueden ayudar. Sin necesidad de faltarle el respeto a nadie y que eso sea mutuo y que se nos sigan abriendo puertas para poder estar mejor y poder ayudar a los que no sacan y que se les de espacio a la gente que realmente lo valore y quiera aprender.
\end{abstract}

En consonancia con la intervención del Alfabetizador 1 días atrás, ella destacó la importancia de aprender cosas buenas, útiles para el futuro, pero además la importancia de poder ayudar a los que no sacan, es decir a los que no lograban acceder o encontrar estrategias para permanecer en el espacio escolar.

\title{
Conclusiones
}

Las intervenciones del Alfabetizador 1 y la Alfabetizadora 2, así como la escritura del compromiso educativo, representaron dos estrategias para "cuidar" el taller frente a la penetración de la "lógica carcelaria" en este espacio. Esta última representó una estrategia concreta frente a la amenaza del personal penitenciario de cerrar el Taller 0 que algún estudiante no pudiera asistir más (sobre todo del Pabellón 7). A partir de los textos los alfabetizadores podrían explicitar el compromiso de los y las estudiantes y proporcionar argumentos concretos para insistir en la continuidad de la actividad pedagógica. Sin embargo, durante el 2017 esto no fue necesario, porque afortunadamente el personal penitenciario no llevó adelante sus presagios.

Por otro lado, como efecto inesperado, estas actividades generaron un reconocimiento hacia el trabajo de los alfabetizadores. Cuando a la clase siguiente llevé los textos del compromiso educativo transcriptos a computadora a la reunión de planificación, los leímos en voz alta y los alfabetizadores se emocionaron mucho. Estaban gratamente sorprendidos de lo que habían escrito los y las estudiantes, de la valoración del espacio, de sus modos de expresarse.

Aunque dispongo de todos los textos escritos en la actividad del compromiso educativo me interesó destacar estos cuatro porque, aunque provienen de los pabellones señalados como opuestos y enemigos, se asemejan en su valoración de este espacio educativo. Durante el transcurso del taller de alfabetización me pregunté, en más de una ocasión, cómo hacían los y las estudiantes jóvenes, provenientes en su mayoría de contextos y trayectorias de violencia y en algunos casos identificados con la figura/estigma de los pibes chorros, para convivir de manera más o menos amable en un espacio educativo con los violines. Si bien no pude profundizar en las identificaciones contrastivas (Barth, 1976; Padawer, 2014) implicadas en los procesos de clasificación e identificación dentro del Penal, los agentes penitenciarios que gestionaban el cupo educativo priorizaban a estos últimos como una estrategia para que la escuela sea un "lugar tranquilo". Por ello, en el taller de alfabetización los y las jóvenes y especialmente aquellos del Pabellón ATR se encontraban con un espacio donde debían interactuar con los violines y en mayor o menor medida, aprendían como sobreponerse a las tensiones inherentes a esta situación.

Esta reflexión puede extenderse, a la convivencia fuera del Penal: ¿cuántas personas en el medio libre y con variadas herramientas socioeducativas, teniendo "información" respecto de causas judiciales de los delitos penales cometidos por sus eventuales compañeros de curso, aceptarían sostener una práctica educativa semanal sin entrar en confrontación o en contradicción? El taller de alfabetización lograba regular ciertos 
márgenes de convivencia con personas detenidas por delitos que son fuertemente condenados socialmente. El espacio educativo del taller de alfabetización, a través de las estrategias enunciadas previamente logró, por momentos, parecerse al CUSAM. Su parecido radicaba en la construcción de un espacio educativo con capacidad de generar procesos reflexivos y compromiso entre los y las participantes. Aun con condiciones materiales e institucionales muy diferentes, los alfabetizadores aceptaron las "reglas del juego" de la gestión penitenciaria, pero también disputaron sus límites demostrando, por ejemplo, que pibes chorros y violines podían contra todo presagio institucional y social, convivir sin matarse.

El clic que el Alfabetizador Uno quería provocar en los y las estudiantes representaba un proceso que ellos/as, por infinidad de motivos, también podrían resistir y rechazar. De hecho, más adelante el Estudiante 8 a pesar de haber mostrado que había "entendido todo" en la actividad realizada en clase, salió de traslado por un enfrentamiento con facas ${ }^{13}$ que se produjo en su pabellón.

La intención genuina del Alfabetizador 1 era la de trasmitir, por lo aprendido en su propio recorrido, que la violencia resultaba funcional a las rejas. Esto era valorado por los y las jóvenes que aprovechaban este espacio educativo y se apropiaban (Rockwell, 2011 [2018] p. 245-248) de manera heterogénea de las interpretaciones de la realidad y las orientaciones valorativas que los alfabetizadores comunicaban. Lo singular del ejercicio escolar de transmitir nuestras concepciones del mundo (Rockwell, 1986, p.25) dentro del taller tenía que ver con que estudiantes y alfabetizadores, exceptuando mi presencia y mis intervenciones, eran pares en la privación de su libertad y en la vivencia cotidiana del encierro. una estudiante de más de 50 años, que sólo vino en algunas ocasiones al taller, en la clase del viernes 11 de agosto, les dijo a los estudiantes:

Ustedes tienen que aprovechar el espacio este de alfabetización porque yo tengo dos hijos presos y agradecería que alguien les hable, así como a ustedes les hablan los alfabetizadores, para que los ayuden a reaccionar. Ustedes tienen que aprovechar este espacio con ellos que les hablan y los ayudan porque en otra cárcel esto no está, los pibes no tienen a nadie que les hable así. (Registro de campo, viernes 11 de agosto del 2017).

A partir de lo expuesto en este artículo, propongo pensar la oportunidad de participar del taller de alfabetización como una categoría social que se opone a la del beneficio de ocupar una silla en la escuela. La oportunidad se vincula a la posibilidad de construir y generar un espacio institucional, sostenido por los alfabetizadores, donde se pueden dar las condiciones para que accedan a la escuela personas privadas de su libertad que habitualmente no lo hacen. Un beneficio, en cambio, es un proceso administrado por los agentes del servicio penitenciario bonaerense, quienes lo conceden como un premio a la buena conducta de acuerdo con la valoración que de ella hacen en la cotidianeidad del penal.

Pero en un sentido más profundo, la oportunidad está ligada a la construcción de un espacio educativo que se busca proteger y conservar porque lo experimentado allí adquiere múltiples sentidos positivos en este contexto. No se trata solamente del interés por avanzar en la progresividad de la pena, sino que, como he demostrado, también implica aprender a gestionar conflictos en un espacio de convivencia de grupos y personas con identificaciones distintivas.

\footnotetext{
${ }_{13}$ Una faca es un cuchillo casero hechos con algún trozo de hierro, elemento cortante y punzante, utilizado como arma blanca (Maduri, 2015, p. 80).
} 


\section{Referencias}

Acin, A y Mercado, P (2006). La educación en el contexto carcelario: una respuesta a las múltiples pobrezas, violencias y procesos de deshumanización. En XVI Encuentro Estado de la Investigación Educativa, Facultad de Educación de la Universidad Católica de Córdoba, Ciudad de Córdoba, Argentina.

Ángel, LA (2015). "La política acá la hacemos nosotros", Relaciones de gobernabilidad y jerarquización en una cárcel Bonaerense (Tesis de Licenciatura). Universidad Nacional de San Martín.

Barth, F (1976). Los grupos étnicos y sus fronteras. México: Fondo de Cultura Económica.

Batallán, G y García, JF (1992). Antropología y participación. Contribución al debate metodológico. Publicar en Antropología y Ciencias Sociales, 1(1), 79-93.

Berenstein, L (2014). El Vínculo Pedagógico en una Experiencia de Alfabetización de Adultos en Contexto de Encierro. Tesis de Maestría. Facultad Latinoamericana de Ciencias Sociales. FLACSO.

Bizarra, R (2002). La escuela en la cárcel: la posibilidad de un espacio abierto en instituciones cerradas. En la Conferencia: La Educación pública en las cárceles, Facultad de Ciencias Sociales y Derecho, Universidad Nacional de La Plata: La Plata.

Calcagno P y Cucut $L$ (2012). Las relaciones de poder entre la universidad de Buenos Aires y el Sistema Penitenciario Federal: construir conocimientos o dominar cuerpos. En Gutiérrez M. (Comp.) Lápices o rejas. Pensar la actualidad del derecho a la educación en contextos de encierro (pp. 13-26). Buenos Aires, Argentina: Editores del Puerto.

Carenzo, S, Acevedo, R y Bárbaro, J (2012). Construyendo oficio: Experiencias laborales de integrantes de una Planta Social de Separación y Clasificación de residuos en el CEAMSE. VII Jornadas de Sociología, Universidad Nacional de La Plata, La Plata.

Comité contra la tortura (2018). Informe Anual: El sistema de la Crueldad XII. La Plata, Comisión Provincial por la Memoria.

Cubilla, W (2015). Experiencia, trabajo y vida al margen de la institución social: el caso de las cirujas del basural de José León Suárez en la Argentina postcrisis 2001.

Daroqui, A (2000). La cárcel en la universidad. En Nari, M. y Fabré A. (Comps.) Voces de mujeres encarceladas. Buenos Aires, Argentina: Catálogos.

De Maeyer, M (1997). Educación en las cárceles: palabras liberadoras. Educación de Adultos y Desarrollo, 49,193-209.

Di Prospero, CE (2019). Pinchar la burbuja. Saberes emergentes y estrategias de aprendizaje de estudiantes detenidas/os en una cárcel bonaerense. Revista Alquimia Educativa, 1(6), 109-124.

Ferreccio, V (2017). La larga sombra de la prisión. Una etnografía de los efectos extendidos del encarcelamiento. Ciudad Autónoma de Buenos Aires, Argentina: Prometeo Libros.
Frejtman, V y Herrera, P (2010). Pensar la educación en contextos de encierro. Aproximaciones a un campo de tensión. Módulo 1. Buenos Aires, Argentina: Ministerio de Educación de la Nación.

Guber, R (2012). La etnografía: Método, campo y reflexividad. Buenos Aires, Argentina: Siglo XXI editores.

Gutiérrez, M (2010). Derechos y sistema penal. La dimensión jurídica de las prácticas educativas en contextos de Encierro. Módulo 2. Buenos Aires, Argentina: Ministerio de Educación de la Nación.

Laferriere, M (2006). La Universidad en la cárcel. Buenos Aires, Argentina: Libros del Rojas.

Laferriere, M (2008). UBA XXII, Programa de Estudios de la UBA en el Servicio Penitenciario Federal: un desafío con más de 20 años de historia. Revista Encrucijadas, 43, 7.

Lave, J, \& Wenger, E (1991). Situated Learning: Legitimate peripheral participation. Cambridge, England: Cambridge University Press.

Lombraña, A, Strauss, L y Tejerina, D (2017) Hacia la construcción de un proyecto pedagógico del Centro Universitario de San Martín (CUSAM). En X Seminario Internacional de Políticas de la Memoria. Centro Cultural de la Memoria Haroldo Conti, Buenos Aires, Argentina.

Maduri, M (2015). Sin berretines: Sociabilidad y movilidad intramuros. Una mirada etnográfica al interior de la prisión (Tesis de Licenciatura). Universidad Nacional de San Martín.

Manchado, M (2012). Educación en contextos de encierro: Problemáticas, miradas e interrogantes en torno al sujeto del aprendizaje y el proceso educativo en las prisiones santafesinas. Revista Latinoamericana de Educación Inclusiva, 6(1), 125-142.

Manchado, M, Routier, M y Chiponi, M (2019). ¿Suspendidos y ejercidos? Dilemas del acceso y ejercicio del derecho educativo en cárceles argentinas. Revista Alquimia Educativa, 6, 148-166.

Martel X y Pérez Lalli $F$ (2007). La escuela en las cárceles: El significado de lo educativo para las personas privadas de la libertad desde la mirada de los docentes. Tesis de Licenciatura. Universidad Nacional de La Plata.

Nieto, M y Zapata, N (2012). Extensión Áulica Unidad 9: Recorrido por una experiencia de formación superior intramuros. Sentidos en juego. En Congreso Desafíos de comunicación/educación en tiempos de restitución de lo público. Universidad Nacional de La Plata. La Plata.

Padawer, A (2014) "Hacer chacra" o "ser de la chacra": identidades contrastivas en el SO misionero. Universidad Nacional de Quilmes. Centro de Estudios de la Argentina Rural. Estudios Rurales, 4(7), 61-80.

Parchuc, JP (2015). La Universidad en la cárcel: teorías, debates, acciones. Redes de extensión, 1, 18-36.

Parziale, V (2012). Una mirada al CENAM desde los aportes de la Geografía y la Ecología. En Revista Prácticas de oficio. Investigación y reflexión en Ciencias Sociales, 9, 1-11. 
Pegoraro, (2012). La cárcel, las cárceles: ¿la educación salvadora? En M Gutiérrez (Comp.), Lápices o rejas. Pensar la actualidad del derecho a la educación en contextos de encierro (pp. 139-156). Buenos Aires, Argentina: Editores del Puerto.

Perearnau, M (2016). Agrandaré mis prisiones. De la causa penal a una causa universitaria, cultural y colectiva. Una elaboración de la experiencia universitaria del CUSAM a partir de las estrategias de subjetivación de los talleres artísticos. En Chiponi, M., Castillo, R. y Manchado, M. (Eds.), A pesar del encierro: prácticas políticas, culturales y educativas en prisión (pp. 123- 132) Rosario, Argentina: Espacio Santafesino.

Pérez, C (2019a). "Yo a investigar la cárcel no vuelvo nunca más" o cómo (no) hacer etnografía en contextos de encierro. Kula. Antropología y Ciencias Sociales, 20/21, 54-59.

Pérez, C (2019b). La Ley Argentina de Estímulo Educativo (26.565/11) y la educación en contextos de encierro. Un análisis desde la perspectiva de la planificación educativa. ESPACIOS EN BLANCO. Revista de Educación, 1(30), 147158.

Pérez, C (2020) ¿Qué se aprende en el taller de alfabetización? Experiencias formativas y aprendizajes situados en un espacio educativo intramuros. Tesis de Doctorado. Universidad Nacional de Tres de Febrero, Universidad Nacional de San Martín y Universidad Nacional de Lanús.

Rancho Aparte, Agrupación artística y social, (2017). Infografía. En la Tercera edición de la Muestra: Arte en territorio, Centro Cultural Haroldo Conti. Buenos Aires, Argentina.

Risler, J y Ares, P (2013) Manual de mapeo colectivo: recursos cartográficos críticos para procesos territoriales de creación colaborativa. Buenos Aires, Argentina: Tinta Limón.

Rockwell, E (1986). De huellas, bardas y veredas: una historia cotidiana en la escuela. En E Rockwell y R Mercado. La escuela, lugar del trabajo docente: descripciones y debates (pp. 10-33). México: Departamento de Investigaciones Educativas del Centro de Investigación y de Estudios Avanzados del Instituto Politécnico.

Rockwell, E. (2009). La experiencia etnográfica. Historia y cultura en los procesos educativos. Buenos Aires, Argentina: Paidós.
Rockwell, E (2018 [2011]) Los niños en los intersticios de la cotidianeidad escolar: ¿resistencia, apropiación o subversión? En N Arata, JC Escalante y A Padawer (Comp.) Vivir entre escuelas: relatos y presencias. Antología esencial (pp. 239363). Ciudad Autónoma de Buenos Aires, Argentina: CLACSO.

Rodríguez, E (2012). La educación en los pantanos punitivos: islotes de organización. En M Gutiérrez (Comp.) Lápices o rejas. Pensar la actualidad del derecho a la educación en contextos de encierro (pp. 259-277). Buenos Aires, Argentina: Editores del Puerto.

Scarfó, F (2006). Los fines de la educación básica en las cárceles en la provincia de Buenos Aires. Tesis de Licenciatura. Universidad Nacional de La Plata.

Scarfó, F (2011). Estándares e indicadores sobre las condiciones de realización del derecho a la educación en las cárceles. Tesis de Maestría. Universidad Nacional de La Plata, La Plata.

Scarfó, F y Zapata, N (2013). Obstáculos en la realización del derecho a la educación en cárceles. Una aproximación sobre la realidad argentina. Cátedra UNESCO de Investigación aplicada para la educación en cárceles.

Schneider, G (2018). Cuando la escuela acontece en la cárcel. Contextos de Educación, 24, 3-13.

Sistema Nacional de Estadísticas sobre Ejecución de la Pena (SNEEP) (2017) Informe Ejecutivo. Dirección Nacional de Política Criminal en materia de Justicia y Legislación Penal.

Sozzo, M (2012). Contra la degradación. La experiencia del Programa de Educación Universitaria en Prisiones, Universidad Nacional del Litoral. En M Gutiérrez (Comp.) Lápices 0 rejas. Pensar la actualidad del derecho a la educación en contextos de encierro (pp. 41-64). Buenos Aires, Argentina: Editores del Puerto.

Suárez, D, Frejtman, V, López Chapato, C, Dávila, P, Bustelo, C y Fernández Valle, M (2012). Entre la cárcel y la escuela: campo de tensiones para la inclusión educativa. Informe Final de investigación. Apoyo a proyectos de investigación del Centro de Cooperación Regional para la Educación de Adultos en América Latina y el Caribe (CREFAL). Buenos Aires: Instituto de Investigaciones en Ciencias de la Educación, Facultad de Filosofía y Letras de la Universidad de Buenos Aires.

Tejerina, D (2016). Estudiar en la cárcel. Lógicas y sentidos de la vida universitaria en el CUSAM. Tesis de Licenciatura. Universidad Nacional de San Martín. 